\title{
UPAYA MENINGKATKAN KUALITAS PENGAMBILAN GAMBAR PROGRAM ACARA PAHLAWAN UNTUK INDONESIA DI MNCTV
}

\author{
Fajar Muharam \\ Fakultas Ilmu Komunikasi dan Bahasa Universitas Bina Sarana Informatika \\ fajar.fhm@bsi.ac.id
}

\begin{abstract}
The Hero Program for Indonesia can be considered a successful program because it can inspire various parties besides it also has educational value. Heroes for Indonesia give awards to selected figures because they have selflessly dedicated their lives to the interests of many people. Camera is one of the important aspects in the production of television program production, the function of the camera is to take / record scenes directed by the director and then visualized by the players who do the scenes. The camera is operated by a television program production crew commonly called cameramen, the cameraman operates the camera according to the direction of the Program director (PD). The method used in this research is descriptive method. Data collection techniques are carried out through interviews, questionnaires, and through literature studies. The results of this study are through the initial habituation of conducting pre-production, production and post-production activities themselves without relying on other teams. constraints. Not only mastering one part but also required to be able to communicate well and be able to work with all relevant agencies. In addition to being fully responsible for all things related tovisuals, the Television cameraman must also be able to provide information to the audience in the form of visuals presented by camera users in all camera positions 1 to 8 cameras.
\end{abstract}

Keywords: Camera, Image capture, Quality, Visual.

\section{A. Pendahuluan}

Kameraman harus mampu memvisualisasikan nilai seni dari sebuah program hingga mampu dinikamati oleh penonton.Kesuksesan acara pahlawan untuk Indonesia juga tidak lepas dari peran kameraman dalam menangkap gambar yang bernilai artistik.Hasil kerja kameraman adalah gambar bergerak yang mempunyai unsur seni dan estetika, untuk mewujudkannya ada kaidah-kaidah yang harus dipenuhi oleh seorang kameraman dalam menjalankan tugasnya.Kamera merupakan salah satu aspek penting dalam suatu pembuatan film, fungsi kamera yaitu mengambil/merekam adegan-adegan yang diarahkan oleh sang sutradara kemudian divisualisasikan oleh pemain-pemain yang melakukan adegan-adegan. 
Kamera dioperasikan oleh kru film yang biasa disebut kameramen, kameramen mengoperasikan kamera sesuai dengan arahan Program director.

Program Pahlawan untuk Indonesia dapat dinilai sebagai program yang sukses karena dapat menginspirasi berbagai pihak disamping itu juga memiliki nilai edukasi. Pahlawan untuk Indonesia memberikan penghargaan kepada figur yang terpilih karena telah tanpa pamrih mendedikasikan hidup untuk kepentingan orang banyak.Figur inspiratif dipilih dari berbagai latar belakang dan asal daerah. MNC menetapkan sejumlah kriteria dengan persyaratan salah satunya adalah figur harus dicalonkan oleh pihak lain. Mengutip lamanfia.ub.ac.id/wp-content/uploads/2016/07/Kerjasama-Usulan-Kandidat.pdf berisi penetapan persyaratan figur, tertulis sebagai berikut:

1. Orang/kelompok orang biasa (ordinary people) yang belum pernah menerima penghargaan nasional

2. Tidak memandang jenis kelamin, usia, suku, agama, latar belakang dan lokasi

3. Kegiatan yang dilaksanakan berdampak nyata, langsung dan luas terhadap masyarakat di sekitarnya

4. Kegiatan yang dilaksanakan tergolong unik dan kadang bertentangan dengan kelaziman (misal: mendaki gunung untuk mengajar, dsb.)

5. Kegiatan yang dilaksanakan berpeluang untuk berkembang dan berlanjut pada masa depan (sustainable) atau mampu membangun kader dan jaringan.

6. Tanpa pamrih, bahkan ikhlas mengorbankan harta dan keluarga.

7. Kehilangan kesempatan yang lebih baik dari segi finansial (misal: sarjana bisa kerja di perusahaan ternama, tapi lebih memilih mengajar penduduk desa).

8. Menjadi inspirasi bagi orang lain untuk berbuat sesuatu yang lebih baik

9. Tidak pernah terlibat dalam kasus Kriminal.

Pahlawan untuk Indonesia banyak diapresiasi oleh berbagai pihak termasuk wakil presiden Jusuf Kalla yang menilai program ini memiliki banyak manfaat.Tentunya kesuksesan program ini juga tidak lepas dari peran serta Kameraman.

Kameramen atau juru kamera/ disingkat sebagai Jurkam ialah orang yang mengoperasikan kamera untuk merekam sebuah gambar film.Kameramen yang bertugas dalam Kapasitas di Proses pembuatan film disebut juga sebagai operator kamera.Kameramen bertangung jawab atas memelihara komposisi seluruh adegan atau bidikannya. Dalam pembuatan sebuah film naratif Kameramen bertugas secara langsung dengan sang sutradara, Penata Fotografi, actor serta crew guna membuat keputusan teknis dan keatif.Namun dalam pembuatan film documenter maupun 
berita, cameramen dipanggil untuk memfilmkan sebuah peristiwa yang tak terekam ataupun tercatat. Biasanya cameramen atau juru kamera ini bekerja sama langsung dengan sang sutradara bisa juga tidak.

Kecakapan sang kameramen yang terpenting adalah mengetahui teknik dalam pengambilan gambar, serta didukung dengan pengetahuan dalam pengambilan gambar.Selain itu cameramen harus memiliki kemampuan pendukung yaitu paham akan memilih sebuah lensa yang cocok.Seorang kameramen harus memastikan bahwa tidak ada kesalahan lakukan saat ia mengambil gambar. Dia harus memastikan bahwa ia mengambil gambar tajam (fokus), komposisi gambar (framing) yang tepat, pengaturan level atau tingkat suara yang sesuai, gambar warna yang sesuai dengan warna aslinya (alam) dan ia harus mendapatkan gambar (foto) yang terbaik.

Kameramen atau juru kamera/ disingkat sebagai Jurkam ialah orang yang mengoperasikan kamera untuk merekam sebuah gambar film.Kameramen yang bertugas dalam Kapasitas di Proses pembuatan film disebut juga sebagai operator kamera.Kameramen bertangung jawab atas memelihara komposisi seluruh adegan atau bidikannya. Dalam pembuatan sebuah film naratif kameramen bertugas secara langsung dengan sang sutradara, Penata Fotografi, actor serta crew guna membuat keputusan teknis dan keatif.

Kameramen haruslah memahami tata gambar dan elemen penting yang harus ada di dalam gambar. Menurut Latief dan Utud (2015) Tata gambar terbagi sebagai berikut: 1) Acuan dasar kamera; 2) Pegerakan kamera; 3)Komposisi; 4) Gerakan Gambar.

Lebih jauh Latief dan Utud (2015) menjelaskan tata gambar dalam teknik pengambilan gambar yang dikenal dengan istilah seperti berikut:

1. Angle Kamera (Bird Eye View, Frog Eye, Straight Angle, Low Angle, dan High Angel.)

2. Frame Size (Close Up, Big Close Up, Extreme Close Up, Medium Close Up, Medium Shot, Knee Shot, Full Shot, Long Shot, One Shot, Two Shot, Three Shot, dan Group Shot)

3. Zoom in/Zoom Out

4. Panning

5. Headroom

6. Noseroom

7. Looking Space

8. Over The Shoulder (OTS)

9. Framming

10. Follow Shot 


\section{B. Hasil dan Pembahasan}

Untuk menghasilkan visual maka program director harus memahami system kinerja seluruh komponen team Pahlawan Untuk Indonesia diantaranya yaitu :

\section{Camera System Kamera EFP (Electronics Field Production)}

systemKamera jenis ini biasanya dipakai untuk produksi dalam ruangan atau studio (in door), yang menggunakan kamera lebih dari satu kamera system, dengan catetan tergantung kebutuhan program. hampir sama dengan jenis pertama.Biasanya 1 (satu) set kamera EFP terdiri atas : Kamera (Lensa, Camera head,View finde), Camera maunting (rolling tripod, pedestal), Kabel kamera (Triax, multiware/multicore),Camera control unit / Base stasion, Remote control panel / Operation control panel, Monitoring System : avefrom monitor, video monitor dan Power supply.

Shot ArrangementPengaturan shot sudah bisa dilakukan pada saat rehearsal, selalu mengecek area shot sesuai dengan yang telah direncanakan. Dengan pengaturan shot ini juga bisa melihat apakah penataan artistik sudah sesuai dengan yang diharapkan. Juga akan berkaitan dengan penataan lighting. Menurut Eva Arifin (2010:169), seorang kameraman alat yang paling utama didalam melaksanakan tugasnya adalah camera dalam bahasa inggris "motion picture camera". Didalam broadcasting televisi keberadaan kamera adalah sesuatu yang paling utama proses dari hasil gambar itulah yang akan ditayangkan didalam program acara televisi di layar kaca.Masing-masing Frame itumerupakan rekaman dari tahapan-tahapan dari suatu gerakan. Semakin cepat perputarannya semakin halus gerakannya, walaupun sebenarnya terdapat jeda antara frame namun kita sebagai manusia tidak bisa menangkap jeda tersebut. Selain itu tv monitor berfungsi sebagai display kamera untuk memonitor hasil pengambilan gambar setiap kamera sehingga bisa diketahui kualitasnya agar dipilih sutradara untuk direkam di master VTR.

Jika tidak mendapatkan shot yang detail, maka caranya dengan menggeser subjek atau menggeser posisi kamera atau dengan melakukan zoom in. Begitu juga kalau ada set yang kurang pas posisinya, set tersebut bisa digeser agar bisa dishoot dengan komposisi yang baik.Oleh karena itu Setiap kamera dipasang satu monitor. 
Master VTR juga membutuhkan dipasang satu monitor untuk mengetahui gambar dari kamera mana yang sedang direkam di VTR. Pemilihan gambar dilaksanakan oleh switcherman dengan memilih menggunakan mixer Video yang telah dilengkapi dengan fasilitas switcer. Perpindahan gambar dari kamera satu ke kamera yang lain menggunakan mode wiper sehingga perpindahan atau transisi dari gambar tidak jumping dan halus. Transisi ada beberapa mode seperti super inpose, wip horizontal, vertikal, diagonal dan sebagainya.

Tentunya tidak terlepas dari segi kemahiran dan keahlian seorang Cameraman tv dalam menangani sebuah alat dan pemahaaman system. Sebagai seorang Cameraman tv harus memahami sebuah perencanaan agar tidak terjadi kesalahan dalam pengerjaan, dan yang terpenting harus memahami lay out set design gambar agar dalam penyusunannya sesuai dengan apa yang sudah di rencanakan.

2. Gambar lay out Panggung PUI (Pahlawan Untuk Indonesia). Dalam penempatan blocking Kamera yang tepat pada tempatnya, menginstal kabel rapih sesuai dengan alurnya dan tidak menimbulkan kesan tidak beraturan. Mengikuti prosedur system dengan melakukan cek dan ricek peralatan, memastikan semua system telah terinstal dengan benar. Melakukan koordinasi dengan berbagai pihak pendukung acara yang terkait.

\section{a. Audio Sound Sistem}

Sound sistem yang terdiri dari mic, mixer audio, equalizer, amplifier, speaker, headpone, tape recorder/cassette recorder, piringan hitam, CD/DVD player dan sebagainya. Sound sistem digunakan untuk keperluan talk back komunikasi antara kameraman dengan sutradara/pengarah dalam rangka koordinasi, pemberian instruksi oleh pengarah kepada kameraman. Talkback juga disalurkan ke ruangruang lain seperti ruang telecine untuk koordinasi pemutaran film, slide dan sebagainya. Sound sistem juga berfungsi sebagai sumber suara utama dan pendukung program. Suara utama adalah suara obyek shoting dan suara pendukung adalah sebagai sumber suara untuk backsound musik, sound efex dan sebagainya. 
Microphone untuk menangkap suara dan diubah menjadi elektris dan disalurkan ke mixer audio.dari mixer disalurkan ke qualizer.Pada mixer dan equalizer suara bisa diolah nadanya sehingga kualitas suaranya baik. Selanjutnya keluarannya disalurkan ke amplifier untuk diperkuat dan keluaranya disalurkan ke tape recorder untuk direkam atau langsung ke Video Tape Recorder (VTR).

\section{b. Lighting Control}

Peralatan ini berfungsi seperti mixer yang berguna untuk pengesetan dan pengaturan cahaya yang ada dalam studio set. Instrumen pengatur cahaya biasanya terletak pada ruang kontrol studio atau pada salah satu sudut di studio. Posisi pengatur cahaya yang berada di ruang kontrol akan memberikan banyak keuntungan, karna penata cahaya dapat langsung berkomunikasi orang-orang di ruang kontrol. Studio televisi dilengkapi dengan sistem pencahayaan yang terdiri atas sejumlah sumber cahaya yang diagntungkan pada langit-langit studio. Setiap sumber cahaya tersebut harus dapat diatur tingkat pencahayaan yang diperlukan untuk setiap program.

\section{c. Tata Panggung (Stage).}

Set Panggung Pahlawan Indonesia.Latar/set/background/television scenaryatau dalam tulisan ini disebut sebagai set adalah apapun yang muncul di belakang subjek/pengisi acara. Set sangat mempengaruhi kesuksesan dari sebuah acara, karenanya set betul-betul harus didesain dengan baik dan dikontrol dengan pengerjaan maupun hasilnya dengan teliti.

Set dapat terbuat dari yang sangat sederhana, seperti backdrop dan dapat juga rumit sehingga melibatkan konstruksi yang besar. Apapun pilihannya, desain yang efektif dan tepat dari sebuah set sangat penting untuk kesuksesan sebuah acara. “.However basic the set materials really are, the end result can appear to the audience as the real thing." Millerson, (2009:211). 
"Sets and stageing are used to create the physical environtment in wich a show takes place. On most shows, the audience's first impression of the program comes form the set." Wurtzel, A and Akcker (2009:447).

\section{d. Waveform}

Alat ini digunakan untuk mengukur kualitas video yang dihasilkan oleh masing-masing kamera serta dari VT.Juga bisa digunakan untuk mengukur audio.Waveform menampilkan graphic yang menjadi parameter atau acuan yang bisa digunakan apakan kualitas video dan audio sudah sesuai harapan atau belum.

\section{e. CCU (Camera Control Unit)}

Ini merupakan satu alat yang bisa mengontrol beberapa fungsi yang ada di kamera. Yang bisa dikontrol atau digantikan fungsinya melalui alat ini diantaranya adalah pengaturan pencahayaan (brightness contrast), temperatur warna (color temperature), kecepatan (shutter speed), white balance serta warna RGB (red, green, blue). Jumlah CCU yang digunakan sama persis dengan jumlah kamera yang digunakan karena masing-masing kamera dikontrol oleh satu CCU.

\section{f. Video Tape Recording (VTR)}

VTR adalah peralatan yg digunakan untuk merekam ( Record) dan memutar (playback) gambar dan suara untuk keperluan siaran. Bagian ini merupakan tempat penyedian materi-materi program siaran yang berbentuk tape atau kaset siap tayang seperti sinetron, program non-drama. VTR berfungsi merekam dan melihat rekaman pada proses produksi, dapat juga digunakan untuk meng-capture (mengubah rekaman dari kaset pita ke digital). Kaset-kaset tersebut di barcode atau dikomputerisasikan sehingga terdapat pembagian segmen untuk sebuah program acara. Kemudian setelah dibagi, di input ke Flexicart atau mesin pemutar materi program. 


\section{g. Master Control (Ruang Kendali Siaran)}

Ruang master kontrol atau Master Control Room (MCR) Televisi atau sering disebut juga sebagai ruang kendali siaran televisi, merupakan ruangan yang berisikan perangkat teknis utama penyiaran dalam mengontrol segala proses siaran stasiun televisi. MCR menjadi pusat dari segala kegiatan produksi siaran yang ada di stasiun penyiaran televisi. MCR sangat penting karena semua materi siaran baik acara secara langsung (live) maupun rekaman di studio, atau kejadian yang langsung dari suatu lokasi di luar studio melalui OB Vanatau mobil siaran, harus melalui MCR terlebih dahulu, sebelum akhirnya dipancarkan ke satelit. Materi siaran berupa iklan, logo stasiun televisi, program-program acara, running text dan sebagainya, semuanya telah disiapkan di MCR untuk ditayangkan.

\section{j). Master control}

Master Control juga bertanggung jawab terhadap kualitas teknis program sesuai dengan standar yang ditentukan. Kegiatan pada Master control dapat dibagi menjadi empat bagian yaitu:

1. Masukan program (p rog ram in put ) Materi program yang masuk ke master control dapat berasal dari studio, satelit, stasiun jaringan, siaran langsung diluar studio atau kurir dalam bentuk video tapeProgram siaran langsung, akan langsung diarahkan ke pemancar, namun sebagian besar materi program harus disimpan dulu sebelum disiarkan. Master control juga menyimpan berbagai jeda (station break) yang dapat berupa iklan, promo (teaser) program selanjutnya, pengumuman, identifikasi stasiun yang muncul di antara program.

2. Penyimpanan program (program storage) Seluruh materi program yang sudah direkam disimpan di Master control atau pada ruang penyimpanan yang telah ditetukan. Setiap program memiliki kode tertentu agar dapat cepat diketahui dan di temukan.

3. Penemuan program (program retrieval)Penemuan program (program retrieval) mencakup kegiatan pemilihan, permintaan dan 
penayangan materi program. Penemuan program ditentukan oleh program log yang berisi daftar perinci setiap program yang ditentukan pada hari tertentu.

4. Program log berisi informasi yang diperlukan bagi efisiensi operasional stasiun penyiaran seperti informasi mengenai waktu tayang program, durasi program, judul program, asal atau sumber program, kode program, jenis program ( langsung atau rekaman ). Program log diterbitkan setiap hari, biasanya lebih dulu satu atau dua hari dari penayangan.Kebanyakan stasiun TV menampilkan program log dilayar komputer, namun terkadang menyediakan pula dalam bentuk hard copy.

\section{k). Traffic}

Traffic ialah jadwal harian untuk suatu stasiun televisiyang berisi catatan yang menunjukan kapan dan apayang sudah diudarakan. Bagi departemen pemasaran, Trafficmerupakan jadwal yang memungkinkan secara akurat mengirimkan tagihan untuk penayangan iklan-iklan.Saat ini, Traffic untuk stasiun televisi sudah sepenuhnya menggunakan program komputeryang dijalankan secara otomatis.Maka seluruh program, promosi dan iklan, bisa dijalankan dan dihentikan melalui komputer. Bila mesin Traffic tidak berjalan sesuai jadwal, maka program tidak bisa diputar pada waktu yang tepat sehingga dapat muncul berbagai persoalan lain, misalnya stasiun televisi dapat kehilangan uang dari iklan yang harus disiarkan.

\section{Out put Pelaksanaan shoting Program Pahlawan Untuk}

Indonesia. Dalam program Pahlawan Untuk Indonesia 2 jam dengan hadiah 100 juta rupiah. terkadang kondisi waktu yang berhimpitan waktu On Air dan kedatangan klien ini tentunya membuat tim produksi cukup repot dalam memenuhi keinginan klien yang tiba tiba berubah dari yang direncakan. Hal yang paling krusial adalah disaat set belum $100 \%$ jadi karena waktu pembuatan menjadi sangat sempit. Namun dengan koordinasi dan dukungan semua pihak akhirnya set kuis dapat diselesaikan 
pada $\mathrm{H}-12$ jam. Dan eksekusi produksi kuis pun dapat terlaksana pada waktu dan jam yang telah direncanakan.

Dengan seperti ini, Sebagai program yang memiliki nilai commercial yang cukup menguntungkan, tentunya berbagai perlengkapan dan peralatan produksi yang sangat mendukung, baik itu kru yang bertugas, akan lebih suport dengan permintaan klien yang berbagi macam permintaan. Namun dengan berjalannya komunikasi yang baik dan intens.maka kesadaran untuk saling suport menjadi point utama dalam modal dan kekuatan tim dalam menjalankan sebuah produksi Program Pahlawan untuk Indonesia di MNC TV.Dalam Sebuah program malam penganugrahan yang telah di setujui oleh produser untuk menyusun budjet anggaran dari pihak sponsor, tentunya dapat menyusuaikan antara pengeluaran budget Program dan budjet produksi program PUI (Pahlawan Untuk Indonesia tersebut. Untuk program PUI (Pahlawan Untuk Indonesia effisiensi biaya dikeluarkan yaitu hanya biaya material set, host (artis), hadiah pemenang, makan dan minum kru serta pengisi acara.Sedangkan untuk equipmet kamera, lighting, audio dan studio merupakan fasilitas yang telah tersedia di mnctv. Selain itu produser sudah memastikan bahwa biaya program tidak melebihi jumlah yang sudah dianggarkan, tujuanya agar tidak mengurangi nilai pada unsur audio visual.

Pada produksi PUI (Pahlawan Untuk Indonesia kami menggunakan multy camera system atau menggunakan 8 (delapan) kamera dalam sebuah adegan / tempat/ setting, terdiri : lensa standart (J20) sebanyak 2 unit, lensa semi wide (J13)sebanyak 3 unit, lensa super wide (J11) sebanyak 1 unit, lensa tele 33 sebanyak 1 unit serta lensa tele 40 sebanyak 1 unit. secara bersamaan merekam sebuah adegan yang dimaksudkan untuk hasil akhir gambar yang kaya dan bervariasi karena berasal dari beberapa kamera yaitu pada sudut pengambilan dan ukuran gambar yang berbeda. Posisi Camera 1 dan 5 lensa standart J20, kemudian posisi lensa tele 33 camera no.2, Kamera no.3. Lensa semi wide, kamera no.4 Lensa tele 40, kmudian Kamera No. 6 dan 7 Hand heald dengan lensa semi wide J 13, kmudian Kamera 8 jimmi Jib sepanjang 12 meter menggunakan Lensa Super Wide (J 11). 
Selain itu pengambilan gambar secara simultan (bersamaan) itu adalah untuk menghemat atau meng efisisensi waktu produksi dan meminimalisir untuk pengulangan sebuah adegan di saat Live atau siaran langsung. dan juga disaat produksi Taping tujuanya untuk mengurangi waktu disaat proses editing tentunya setelah pengambilan gambar selesai, Walaupun memakan waktu yang cukup lama proses pemasangan kamera dibandingakan dengan pemasangan single kamera, ini akan lebih efisien dalam waktu dan biaya produksi.

Dari perjalanan Program Pahlawan Untuk Indonesia di mnc tv ada beberapa hal positif yang patut menjadi dipertahankan, yakni Kejelasan informasi dan instruksi dari GM (General Manager) produksi kepada klien ke seluruh team produksi yang akan mempermudah proses produksi dan Kesiagaan aktif seluruh tim produksi menjadi kekuatan tambahan untuk mewujudkan produksi dengan keinginan klien dan General Manager (GM).

Secara umum produksi Program Pahlawan Untuk Indonesia berjalan lancar dan profesional.Banyak hal yang dapat dipetik dari pelaksanaan program ini, diantaranya pentingnya komunikasi dan koordinasi antar seluruh lini. Dan kesamaan visi apapun tidak akan terlaksana dengan baik tanpa keikhlasan, kesabaran dan dukungan positif dari berbagai lini.Pakaian yang dikenakan host acara ini disesuaikan dengan warna dari sebuah tema di setiap tahunya.

Setelah semua rangkaian proses in put dan outpun sudah berjalan maka sudah tentu akan ada hasil dan kemasan yang maximal, tentunya apa yang di rencanakan sesuai apa yang sudah di konsep baik dari arahan GM (General Manager), lalu Direktur Program, klien dan kepada tim Produksi Program Pahlawan Untuk Indonesia di Mnc tv dalam durasi 2 jam.

\section{Simpulan}

Pada Tahap pra produksi Program Pahlawan Untuk Indonesiadi Mnctv. memakan waktu sekitar 3 bulan.Tahap pra produksi meliputi pencarian ide, perencanaan serta persiapan. Hal yang memakan waktu paling lama ialah saat 
pembuatan rundown sebab banyak hal yang mesti disesuaikan antara ide dengan kondisi tekhnis dan non tekhnis.

Tahap produksi merupakan tahap realisasi Pergerakan Kamera Video. Dua kategori pergerakan kamera: gerakan kamera berada di atas penopang (tripod) dan gerakan kamera dengan body-nya. Gerakan kamera di atas penopang (tripod): panning (gerakan kamera video secara mendatar/horizontal ke arah kiri maupun kanan), tilting (gerakan kamera video secara vertikal ke arah atas dan ke bawah).Gerakan kamera video dengan body-nya: tracking, craning. Komposisi Framing diperlukan untuk mendapatkan gambar yang baik, dapat berbicara, mempunyai makna, lebih hidup, dan mewujudkan visual film agar tidak monoton. Selain itu komposisi framing bertujuan untuk memberi informasi aksi maupun interaksi subyek dan mengarahkan fokus penonton kepada subyek yang sedang direkam dengan aksinya tersebut.

Pasca Produksi, Usai tayang, seluruh kru berkumpul untuk mendengarkan evaluasi yang diberikan oleh Produser dan klien. Sehingga pada proses produksi berikutnya akan lebih baik dan tidak terjadi lagi hal hal yang tidak di harapkan.

\section{REFERENSI}

Arifin, Eva. 2010. Broadcasting To Be Broadcaster, Cetakan Pertama. Yogyakarta: Graha Ilmu.

Apple, James M. 1990.Tata Letak Pabrik Dan Pemindahan Bahan Edisi Ketiga. Bandung: ITB

Cangara, Hafied. 2006. Perencanaan Dan Strategi Jalan Sutra. Meteologi Penelitian Kualitatif. Bandung: Remaja Rosdakarya.

Baksin,Askurifai. 2006. Jurnalistik Televisi, Cetakan Pertama. Bandung: Simbiosa Rekatama Media

Balai Diklat TVRI MMTC ( Multi Media Training Centre). 1996. Yogyakarta : Balai Diklat TVRI

Fachruddin, Andi. 2016. Manajemen Pertelevisia Modern,Ed-1. Yogyakarta: Percetakan Andi 
Latief Rusman, Utud Y. 2015. Siaran Televisi Non-Drama. Kreatif, Produksi, Public Relations, Iklan. Jakarta: Kencana.

Marcel, Danesi.2010. Pesan, Tanda, dan Makna, Buku Teks Dasar Mengenai Semiotika Dan Teori Komunikasi. Yogyakarta: Percetakan Andi

Naratama. 2004. Menjadi Sutradara Televisi ,Cetakan Pertama. Jakarta: Grassindo.

Riswandi. 2008. Dasar-Dasar Penyiaran, Cetakan Pertama. Yogyakarta: Graha Ilmu.

Suprapto, Tommy. 2006. Berkarier Di Bidang Broadcasting, Cetakan Pertama. Yogyakarta: Media Pressindo.

Http://Www.Pppgkes.Com, 20 Februari.

Http://Www.Suaramerdeka.Com, 25 September

Http://En.Wikipedia.Org/Wiki/Kameramantv Broadcasting

http://fia.ub.ac.id/wp-content/uploads/2016/07/Kerjasama-Usulan-Kandidat.pdf

www.mnctv.com 